\title{
Calendar
}

\section{The European Spine Society: The Acromed Prize for Spinal Research 1997}

\author{
September 10-13, 1997, \\ Meeting of the European Spine Society in Kos, Greece
}

To promote research in Spinal Disorders, AcroMed will present a prize of Dfl. 10.000 - at the 8th Annual Meeting of the European Spine Society in Kos, Greece, September 10-13, 1997.

Applicants have to submit a full written paper in English ready for publication including figures and references, reporting an original study not previously published nor submitted for publication elsewhere.

Closing date: July 15, 1997.

At least one of the authors of the winning paper has to present the paper personally at the meeting in Kos. By applying, the authors agree to the publication of the paper in the European Spine Journal under the heading of the AcroMed Prize for Spinal Research 1997, should they win the prize.

Original manuscripts with two copies are to be sent to: Mrs. J. Reichert-Schild

Seefeldstrasse 16

CH-8610 Uster

Switzerland

Fax: +4119941403 